\title{
Bitácoras y portafolios en los Talleres de Diseño Arquitectónico
}

Alejandra Torres Landa López

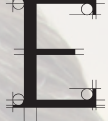

objetivo general del Plan de Estudios de la Licenciatura en Arquitectura de la Universidad Autónoma de Aguascalientes (UAA) es formar profesionales "de la arquitectura en los ámbitos del Diseño y la Edificación de espacios habitables desde lo local hasta lo global, con una orientación humanista sensible a los problemas del entorno y capacidad para interpretar los factores socio-culturales y tecnológicos a efectos de mejorar la calidad de vida con base en criterios sustentables" (UAA, 2012: 1).

Los Talleres de Diseño Arquitectónico son la columna vertebral de dicha carrera, pues motivan a los estudiantes a integrar los conocimientos, habilidades y actitudes aprendidas y desarrolladas durante la currícula. En estas materias se les pide a los estudiantes que desarrollen proyectos arquitectónicos a diferente escala y con alcances específicos, dependiendo del nivel en el que se encuentre el estudiante. Estos ejercicios son un pretexto para iniciar la discusión, en la que se pide a profesores y estudiantes aporten críticas constructivas, intercambiando opiniones, conocimientos, técnicas y experiencias que enriquezcan el proceso de aprendizaje (Torres, 2014).

Estas materias de diseño tienen características especiales, ya que poseen un gran porcentaje de carga práctica; por tal motivo, y con el fin de fortalecer el proceso de aprendizaje del estudiante, desde hace varios años se introdujo el uso de la bitácora, y se solicita la entrega de portafolios académicos al finalizar cada semestre. Lo anterior, es un esfuerzo que se logró como resultado del trabajo de la Academia de Diseño Arquitectónico.

El objetivo de este artículo es resaltar las diferencias entre bitácora y portafolio, ya que en algunos casos se identifican como sinónimo, lo que provoca que únicamente se repita el contenido de una en la otra, es decir, que si el estudiante exclusivamente traslada lo escrito en la bitácora en un formato diferente para presentarlo como portafolio al final del semestre, se pierde la riqueza de cada una de estas herramientas.

\section{Bitácora y portafolio. Herramientas que apoyan y fortalecen el aprendizaje}

En las materias de los Talleres de Diseño Arquitectónico se realizan clases teóricas frente a grupo para aclarar contenidos, cuyos conceptos se aplicarán posteriormente en ejercicios prácticos dentro del taller, los cuales se revisan en grupo e individualmente a fin de guiar el proceso de diseño de cada estudiante. 
$\mathrm{Al}$ reconocer la evaluación como parte integral y continua del proceso educativo, como bien lo señala el Modelo Educativo Institucional (MEI, 2006: 18), es que la Academia de Diseño Arquitectónico diseñó un cuadernillo para dar seguimiento al trabajo durante cada sesión, a éste se le llama Bitácora de Diseño Arquitectónico (Imagen 1), ya que una bitácora es el registro diario de actividades o tareas que se llevan a cabo durante el desarrollo de un trabajo, proyecto o estudio en un tiempo determinado (Buitrago \& Sierra, 2012).

En esta bitácora, el estudiante escribe su nombre y señala la actividad, su objetivo específico, el tema, etapa y asesor que guía el aprendizaje. Hay un espacio para apuntes gráficos y otro para escritos que complementan lo visto durante la sesión, lo que permite reconocer el avance diario, desarrollando habilidades para escuchar, interpretar y aplicar el conocimiento (Imagen 2). ${ }^{1}$

Para mejorar el aprovechamiento de la bitácora (Weimer, 2013) se sugiere al profesor:

1. Identificar el concepto clave para cada sesión, puede ser una palabra o una frase que los estudiantes deben anotar en su bitácora.

2. Solicitar al estudiante que busque en su bitácora algún concepto anotado que puede utilizar en su propuesta de diseño.

3. Dar tiempo a los estudiantes para realizar las anotaciones, escribir comentarios y dibujar croquis.

4. Antes de iniciar una revisión, ver juntos las notas de la sesión anterior y saber si se tomaron en cuenta.

5. En algunos momentos, se puede exponer ante el grupo una de las bitácoras.

6. En otras ocasiones, dejar tiempo al finalizar la clase para intercambiar notas entre compañeros, y pedirles que identifiquen semejanzas y diferencias.

7. Emplear croquis es fundamental para desarrollar la competencia del dibujo a mano alzada y la expresión de ideas del arquitecto, por lo que es importante insistir que siempre esté presente en las bitácoras.

1 Bitácora de Beatriz A. Acevedo de Lara, estudiante de Diseño Arquitectónico II, semestre agosto-diciembre 2013.
A diferencia de la bitácora, el portafolio académico es un conjunto de evidencias que puede ser agrupado por una o varias personas, para mostrar el resultado de las actividades desarrolladas en un curso académico o en un proyecto. Se pueden elaborar portafolios tradicionales, almacenando físicamente los trabajos; o digitales, utilizando software para crear versiones electrónicas o en línea.

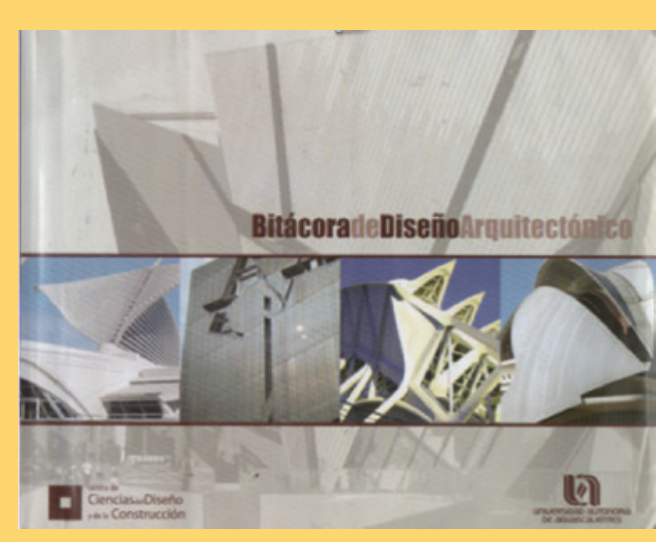

Imagen 1. Portada de la Bitácora

de Diseño Arquitectónico utilizada en la UAA. Foto ATL.

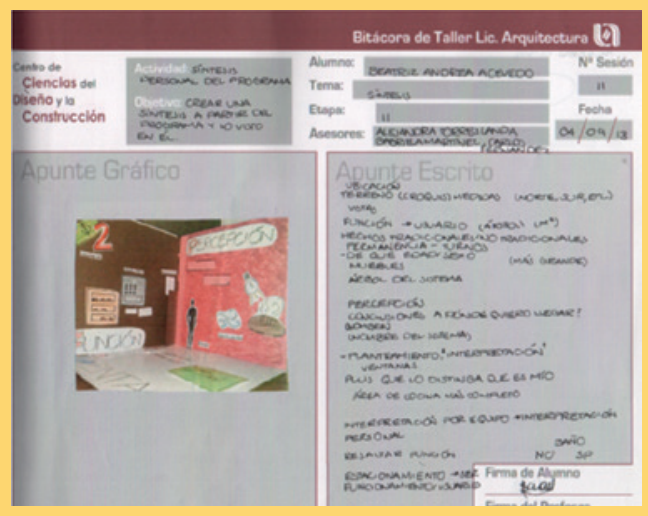

Imagen 2. Bitácora de una estudiante de Diseño Arquitectónico II (2013). Foto ATL.

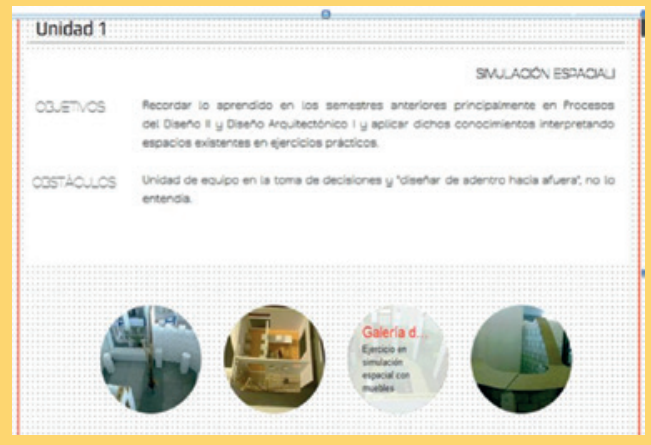

Imagen 3. Portafolio en Wix de un estudiante de Diseño Arquitectónico II (2013). Foto ATL. 
Los portafolios pueden ser de diagnóstico, orientación, desarrollo, valoración o evaluación de conocimientos y habilidades; permite documentar los procesos de enseñanza y aprendizaje, evaluar procesos y producciones, dar seguimiento a la evolución de las competencias. Asimismo, ayuda a motivar a los estudiantes a reflexionar sobre su propio aprendizaje, y hace partícipe a los estudiantes en el proceso de evaluación (Gutiérrez, 2009).

Los portafolios académicos dan cuenta del cumplimiento de los objetivos educativos, y son una herramienta que se utiliza como evidencia para generar una evaluación más objetiva en los Talleres de Diseño Arquitectónico, lo que permite reconocer tanto el proceso como el producto final.

Para enriquecer el uso de portafolio, al finalizar cada etapa (unidad o proyecto), el estudiante debe hacer un alto y revisar los apuntes de la bitácora para retomar los elementos más importantes y llevarlos a su portafolio, donde incluirá una reflexión sobre lo aprendido y los puntos en los que deberá reforzar para continuar en la siguiente etapa. Se pueden utilizar varias estrategias, por ejemplo un cuadro de FODA, señalando fortalezas, oportunidades, debilidades y amenazas del ejercicio evaluado, de tal manera que en la siguiente etapa puedan servir de plataforma para impulsar y mejorar el ejercicio; un diagrama de Venn también puede ser útil, si se interrelacionan los aciertos y debilidades que se tuvieron durante el ejercicio.

Al concluir el semestre agosto-diciembre de 2013, los estudiantes de Diseño Arquitectónico II entregaron portafolios muy interesantes. Algunos se elaboraron en PowerPoint entregándolos en $\mathrm{CD}$, otros utilizaron herramientas de la Web 2.0, como Prezi o Wix, mostrándolos en línea ${ }^{2}$ (Imagen 3 ).

\section{Conclusión}

Es necesario utilizar las bitácoras y los portafolios como dos estrategias distintas, que al complementarse enriquezcan el proceso

2 Ejemplos de portafolio en línea elaborados por estudiantes de tercer semestre de arquitectura: de Andrea Spínola Solís: http://prezi.com/wpn8bdtpjoyv/diseno-arquitectonico/, de Mariana Peredo Mier: http://prezi.com/s74pez_mn6r3/ diseno-arquitectonico/, de Lucero Cabañas Melo: http:// melitoinc.wix.com/3arq\#!portfolio/czoy, o el de Marcelino Vázquez del Villar: http://mvvags.wix.com/marceportfolio. de aprendizaje. El estudiante debe llevar una bitácora completa, día a día, registrando comentarios de los profesores y compañeros, así como anotando reflexiones propias, incluyendo gráficos e imágenes que apoyen el proceso de diseño y de aprendizaje en cada sesión. El portafolio, de ser utilizado como evidencia al final del semestre, debe ser un pretexto para que el estudiante reflexione sobre su propio proceso de aprendizaje.

La unión de ambas herramientas proporcionará al profesor indicadores objetivos para guiar, de manera más certera, al estudiante a fin de que logre los objetivos del aprendizaje.

\section{Fuentes de consulta}

Buitrago, C. y Sierra, L. (2012). La bitácora. Feria de la ciencia, la tecnología y la innovación 2012, presentación digital en Slideshare. Consultado en diciembre de 2013 en: http://www.slideshare.net/ clemen07/bitcoraportafolio.

Gutiérrez Marfileño, V. E. (2009). Diseño de evaluación con Portafolio. Materiales de es-tudio para el Diplomado en Formación de Competencias Básicas para la Docencia. México: UAA.

Torres Landa L., A. (2014). Blended learning, and Educational Cocktail: social interaction in a mixture of learning environments. Presentación de apoyo para la sesión de Poster presentada en la Reunión Anual educause ELI 2014. Recuperado en diciembre de 2013 en: http://www.slideshare.net/maestralejandra/educationalcocktail-29577426.

UAA. (2012). Plan de Estudios de la Licenciatura en Arquitectura. Recuperado en diciembre de 2013 en: http://www.uaa. $\mathrm{mx} /$ direcciones/dgdp/catalogo/ciencias dis_const/arquitectura.pdf.

UAA. (2006). Modelo Educativo Institucional. México: UAA.

Weimer, Maryellen. (2013). Tips for Developing Students' Note-taking Skills, in Teaching Professor Blog. Recuperado en noviembre de 2013 en: http://www. facultyfocus.com/articles/teaching-professor-blog/tips-for-developing-studentsnote-taking-skills/. 